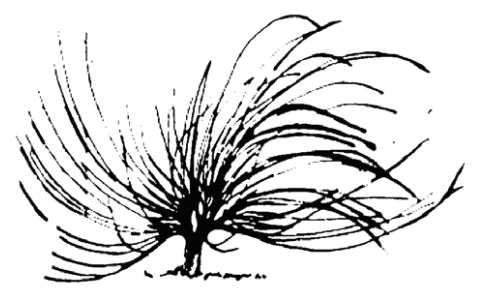

\title{
Teoría de la Educación y Filosofía
}

\author{
Ricardo Antonio Villalobos Paniagua ${ }^{1}$ \\ Universidad Estatal a Distancia \\ San José, Costa Rica \\ ravp1970@yahoo.com
}

\begin{abstract}
Resumen
La Teoría de la Educación no puede desligarse de la Filosofía, así como es necesario que el docente contemporáneo posea principios y conceptos filosóficos, sean antropológicos o epistemológicos. Acá el papel de la Filosofía de la Educación le brinda al docente insumos cognitivos que enriquecen su práctica docente. El siguiente ensayo considera tal simbiosis: educación-filosofía, elaborando ideas que llevan a la reflexión del devenir educativo como proceso teórico, y desde Esta a la práctica pedagógica, lo cual genera nuevas teorías didácticas, todo enmarcado en esa necesidad de que la educación, en general, particularmente desde la formación docente universitaria, distinga en la filosofía su sustentante no solo epistemológico sino vital también.
\end{abstract}

Palabras clave: educación, filosofía, teoría, modelos, pedagogía, epistemología

(c) (i) $(9)$

Recibido: 9 de setiembre de 2014-Aprobado: 13 de abril de 2015

1 Docente en la Universidad Estatal a Distancia (Cátedras de Filosofía y de Métodos de Investigación y Educación a Distancia); en la Escuela de Estudios Generales de la Universidad de Costa Rica, sección Filosofía y Pensamiento; ha sido docente en el CIDE de la Universidad Nacional; director de tesis y lector interno en el Programa de la Licenciatura en Docencia de la Universidad Estatal a Distancia; M. Ed con énfasis en Docencia Universitaria (UNA); Lic. En Filosofía (UNA); Lic. En Ciencias de la Educación con énfasis en Docencia (UNED); Bach. En Filosofía y Humanidades (Universidad Católica de Costa Rica). 


\begin{abstract}
The Theory of Education cannot be disengaged from Philosophy, so it is necessary for the teacher contemporary to have philosophical principles and concepts, be them anthropological or epistemological. The role of philosophy education gives to the teacher cognitive a input that enriches his or her teaching practice. This essay consideres such symbiosis as education-philosophy, elaborating on ideas that lead to reflection on the development of education as a theoretical process, and from this to pedagogical practice, which generates new didactic theories framed in the necessity that education in general indentifies in philosophy its epistemological and vital basis particularly in university teaching.
\end{abstract}

Keywords: education, philosophy, theory, models, pedagogy, epistemology

\title{
Introducción
}

José Michel Salazar (2006) considera que se puede hablar de Ciencias de la Educación desde la teoría educativa de John Dewey (18591952), pues Deweyidea la posibilidad de esta denominada Ciencia de la educación, en tanto, es conocimiento pragmático, positivista y científico, sin dejar de concordar con los aportes fundamentales de ciencias como la sociología, la psicología y la economía a la educación. Salazar (2006)no habla de una Ciencia de la educación separada de esas ciencias anteriormente citadas, sino por estas disciplinas que se constituirá la Ciencia de la educación concretamente. No obstante, este tema aún está en estado de discordia entre teóricos y filósofos de la educación.

De parte del autor de este ensayo, y como tesis fundamental, se acude a visualizar lo siguiente: "la relevancia de la epistemología filosófica en, y para la Educación en sus diversos énfasis curriculares, como preparación y formación para los futuros y actuales, docentes, ello desde los cursos universitarios o capacitaciones. Es decir, que no falte el curso de epistemología en toda carrera de educación, inclusive en sus posgrados."

La tesis que sustenta este ensayo, pues así se solicita, acontece debido a una percepción cognitiva del autor que corresponde a un sentido 
olvido, consciente o inconsciente -que raya con la ignorancia-, de la importancia histórica de la filosofía y su papel protagónico en el devenir educativo de todos los tiempos, sintomáticamente con la epistemología filosófica, para el caso específico en las Ciencias de la Educación.

En "el interés" de la filosofía por participar en el acontecer de la pedagogía y la didáctica, en el cual de por sí la filosofía es precursora de sistemas (e instituciones) educativos, es que, esta, ha generado un discurso acerca de lo educativo, la denominada: Filosofía de la Educación, que presenta en su relación con la Teoría de la Educación.

Desestimar ese papel preponderante, didáctico, teórico y formativo de la filosofía provoca que los sistemas educativos universitarios que preparan a los docentes, y les pretenden seguir capacitando, se conviertan en dadores transmisores de datos, que sin el aporte epistemológico esencial no podrían ser reflexionados, esos datos, con el dinamismo y exhaustividad cognitiva que la epistemología provee, máxime que ella capacita a "leer" el conocimiento a la luz de la actualidad de cada época, algo que la Filosofía de la Educación ostenta en sus competencias: proveer de estrategias para la reflexión y análisis de las realidades educativas.

Además, se acude y con el fin de concretar la tesis anterior, a definir que la Teoría de la Educación nos dirige hacia una concepción del: educar como un arte, si consideramoseste, el arte, como un conjunto de conocimientos que le permiten al ser humano realizar de mejor manera una acción. De hecho Mario Bunge (1998) explica que:

Si "arte" significa una feliz conjunción de experiencia, destreza, imaginación, visión y habilidad para realizar inferencias de tipo no analítico, entonces no solo son artes la medicina, la pesquisa criminal, la estrategia militar, la política y la publicidad, sino también toda otra disciplina. (p. 83)

Para así sumar, el decir, que la filosofía es un modo de hacer arte también, pues a través de la reflexión y el análisis de la realidad es que interpretamos el mundo, a la naturaleza, que como la ciencia -sabiéndose que la filosofía no es estrictamente ciencia pues su método no es el científico sino el especulativo, aunque sí proveedora de ciencia, debido a que sus reflexiones y consecuentes argumentos conllevan a nuevas teorías epistemológicas, así como, y especialmente, en sus aportes de lo ético como discurso imperativo a toda ciencia, a lo cual, por ende, la 
filosofía le contribuye- legaconocimiento. La filosofía, en la Filosofía de la Educación, le proporciona a la Teoría de la Educación de una epistemología educativa. No se pueden desligar Filosofía de Educación.

\section{Definición de Teoría de la Educación}

Definamos algunos conceptos, previamente que allanan el cometido de esta exposición:

\section{Definición de "Teoría"}

Etimológicamente, el conceptoteoríaderiva del griego (theoría $=$ pensamientoespeculativo). Pero la teoríapuedeserdefinida, básicamente comoconjunto de ideas quepretendenexplicar un fenómeno a partir del raciocinio, pues reflexión de esos fenómenos, o hechos.

Mario Bunge (1998), acerca del asunto en cuestión, expone que las hipótesis están incorporadas en las teorías, o tienden a estarlo, y que las teorías se interrelacionan conformando lo que él llama: "cultura intelectual". Además de lo importante de numerososhechos, experiencias, que confirmen esas hipótesis para generar credibilidad en la teoría, porque las teorías deben adecuarse a los hechos (pp. 78-80).

La meta final de una investigación científica estima Bunge (1984), es descubrir las leyes de la realidad con el fin de utilizarlas para explicarla y predecirla, por lo tanto, si no hubiesen teorías los datos serían superficiales e inexactos, pues son las teorías las que permiten "diseñar observaciones, mediciones y experimentos" (p. 121).

\section{Definición de "Educación"}

Este concepto deriva del latín: educatio-onis, lo cual puede definirse como:Instrucción por medio de la acción docente.

La educación es el acto, por excelencia, que genera en el ser humanola disposición a la vida social y «civilizada»; la educación hace o construye cultura. La educación es comprendida comúnmente como pedagogía, sobre esto Michel Salazar (2006)considera que el término es también algo oscuro en su definición y comprensión porque etimológicamente el concepto pedagogía proviene del griego paidos que significa niño y de agein que significa guiar o conducir (p. 146), por lo que 
solamente referiría a la educación de niños. Pero, contemporáneamente, el concepto es aplicado a todo tipo de proceso educativo formal: primaria, secundaria y educación superior.

La educación, como proceso formal, conlleva a ser comprendida en tanto acto de reciprocidad en el dar y recibir conocimiento, es decir, el conocimiento se puede construir debido a y por esa reciprocidad informativa de los cognoscentes, muy a partir del proceso de enseñanza-aprendizaje que se establece entre docente y discente,y desde un currículo, programa o plan de estudios establecido.

Aunque no puede dejar de denotarse que existe educación "conducida", a pesar de que tiende a un adoctrinamiento, y lo hay también, muy común de hecho en todos los sistemas educativos formales, conlleva a transmisión de las informaciones. Pero en realidad todo conocimiento es transmitido, es heredado, es legado. Sin embargo, este puede conducir a construir nuevo conocimiento.

En realidad, todo conocimiento se transmite, el objetivo de una epistemología educativa será concretar que ese dato transmitido sea releído acorde con la nueva realidad y sus pertinentes nuevas necesidades, con el fin de transformar al mundo desde una lectura que se recapitula.

Así pues, no puede decirse que el conocimiento es solamente construcción, como algunos pretenden visualizar y defender, es absurdo, de hecho cada quien con sus argumentos busca "variar" una opinión queriendo imponer la suya (todos queremos poder), los docentes lo hacemos sin duda también, todo docente busca defender su pensamiento. Consciente o inconscientemente influimos en otras conciencias, inclusive cuando solicitamos construcción de conocimiento, lo hacemos con el solo discurso que creemos válido, hasta verdadero, y no está mal. No considerar ello de parte de muchos pedagogos es consecuencia de esa "falta de epistemología" en su preparación docente.

Aunado a lo anterior, y en concordancia con lo explicado, es bien sabido que hay ciencias, por su método y naturaleza esencial, que requieren de métodos conductivos para su aprendizaje, como sucede con la química, la física o en el deporte, por citar. Más aún, se da la transmisión de tradiciones o pensamientos en las culturas, por ende, de ideas, por ejemplo, a lo que aún recurren culturas actuales o ancestrales religiosas como la hebrea y la musulmana, quienes acuden a las escuelas rabínicas o a las madrazas respectivamente, quienes aún continúan enseñando la Torá y el Corán por la transmisión del "dato revelado", memorístico y repetitivo. 
Es decir, el conocimiento se construye y se transmite, o viceversa, y esto es tema de la epistemología. Y el hecho de uno u otro no le impide a la Filosofía de la Educación descubrir "su bien", en una y en otra, a lo que quizás actuales teóricos de la educación no acuden en su razón, por considerar solamente una posibilidad: el conocimiento se construye, con lo que se cae en un problema epistemológico, e incluso didáctico, a lo que la filosofía, y la Filosofía de la Educación, podrían ayudar a subsanar por la epistemología.

Se sostiene así la tesis del ensayo, el olvido de la filosofía, de la Filosofía de la Educación, por lo tanto, de la epistemología filosófica acaece en serios "baches" pedagógicos y cognitivos, evidenciando dogmatismos entre los pedagogos y sus didácticas; incluso ya se ha llegado a "satanizar" a la memoria, otro dilema preocupante entre nuevos pedagogos, pues la memoria es el método natural por el que el cerebro aprehende, este es otro dilema de carácter epistemológico, que sin epistemología no se puede solucionar.

El docente requiere descubrir que siempre existen, al menos, dos posibilidades de explicación, de decidir asumir, la epistemología le posibilita a ello y con esto evita dogmatismos inconsistentes.

\section{Definición de "Filosofía"}

Históricamente, el origen de la filosofía occidental se dio en la Antigua Grecia en el siglo VII A.C.Para Sócrates (470-399 a.C), la filosofía es "un conocerse a uno mismo"; para Platón (427-347 a.C), discípulo de este, es "estudio del mundo de las ideas", o "de las ideas"; para Aristóteles (384-322 a.C), discípulo de Platón, es "conocimiento desde lo metafísico y lo empírico a través de la razón"; o bien, para San Agustín (354-430), es el "momento oportuno para autoconocerse, en tanto, soy alma que va en busca de su encuentro con Dios". Por su parte, San Buenaventura (1221-1274), franciscano italiano, consideraba que la filosofía es "itinerario de la mente hacia Dios".

La filosofía, como concepto, proviene del griego (philos= amor y sofía = sabiduría). Xavier Zubiri (2010), explica en su primera Lección sobre Aristóteles, y conforme lo anterior, por lo tanto, la filosofía es, o significa, el gusto, el amor de la sabiduría y del conocimiento (p. 16).

En su segunda lección: Lección sobre Kant, aclara que para Emmanuel Kant (1724-1804) la filosofía es metafísica, por lo tanto, un 
saber de lo trascendente: “(...) la verdad trascendental y la verdad trascendente hechas posible por la estructura misma de la razón: he aquí la filosofía para Kant” (pp. 106-107).

Mientras que en su Lección sobre A. Comte (1798-1857), define que para este la filosofía es, en resumen, reflexión sobre la sabiduría que brota del espiritu humano como razón pública o social (filosofía positiva) que construye la moral, moral nacida de la experiencia histórica (pp.144-148).

Cuando Zubiri aborda la definición de filosofía en su Lección sobre Bergson (1859-1941), explica que para él la filosofía es un saber positivo de la realidad, esto significa que para Bergson hay hechos inmediatos que aunque no son "hechos científicos en el sentido de las ciencias" sí son positivos (reales y válidos de análisis), este es el caso del saber filosófico (p. 163), que a la vez se fundamenta en un "gran órgano mental para filosofar" (su método): la intuición, que es "el acto que nos coloca dentro de las cosas. La intuición para Bergson en síntesis es aprehensión inmediata, una simpatía (sentir), una simbiosis con las cosas para aprehenderlas (p. 167).

En la Lección sobre Husserl (1859-1937), Zubiri plantea que la filosofía es, para Husserl, una experiencia fenomenológica (fenomenología), una "ciencia estricta y rigurosa de la esencia. La filosofía no es un sistema racional y lógico de proposiciones y demostraciones, sino que es evidenciación intuitiva" (p. 221)

Educación, como proceso en general, sin asirse a la filosofía es "quedar renca", pedagogía sin epistemología filosófica es actitud sin discernimiento, sin reflexión.

\section{Definición de "Ciencia"}

El conceptociencia,del griego epísteme y del latín scientia,puede sercomprendido como conocimiento en su traducción literal. Por lo tanto, la ciencia es, en sí misma, eso: conocimiento o adquisición de este. Mario Bunge (1998) define lo que la ciencia es, de este modo:

Mientras los animales inferiores solo están en el mundo, el hombre trata de entenderlo: y, sobre la base de su inteligencia imperfecta pero perfectible del mundo, el hombre intenta enseñorearsede él para hacerlo más confortable. En este proceso, construye un mundo 
artificial: ese creciente cuerpo de ideas llamado "ciencia", que puede caracterizarse como conocimiento racional, sistemático, exacto, verificable y por consiguiente falible. Por medio de la investigación científica, el hombre ha alcanzado una reconstrucción conceptual del mundo que es cada vez más amplia, profunda y exacta. (p. 11)

De este modo, puede identificarse a la ciencia como ese deseo natural, en el ser humano, por conocer, y conocer para mejorar su estado de vida, para transformarlo a través dela investigación científica, la cual parte de teorías e investigaciones, es decir, de presupuestos racionales que buscan el entendimiento de la realidad para su aprovechamiento.

La epistemología filosófica provee a la ciencia de razón de ser, pues emite sobre ella supuestos necesarios para dirimir sus teorías, con esto quiero decir que la ciencia sin apetito reflexivo proveído por el arte filosófico suele decaer en discurso poco dado al análisis categórico y con ello a discursos irracionales. El científico ha de hacer reflexión de sus discursos, pues "hacer práctica filosófica" tanto como de sus actos (desde el análisis ético).

La relevancia de la filosofía, especialmente, de la epistemología, para la ciencia está en darle puntos de referencia para la reflexión, y de discusión al que discurre en argumentaciones.

Ergo, y para el interés de este ensayo, las ciencias de la educación sin filosofía, sin epistemología, tienden a emanar meras teorías no acordes a las distintas realidades, cuando cada una de ellas, esas teorías educativas, merecen y requieren de un análisis particular, es decir, de un estudio epistemológico particular, de perspectiva, justo lo que la epistemología propicia.

Educadores sin conocimiento y prácticas epistemológicas -sin posibilidades de perspectiva- se verían convertidos en meros transmisores de datos, a los que les costará invitar, a sus estudiantes, a una nueva reconstrucción de la realidad a partir de la introspección del dato dado, a una relectura de lo que acontece, pero desde el dato enseñado, y esto para lograr transformar el mundo, incluso desde materias de tipo conductista, generando creatividad pragmática.

La epistemología enseña a descubrir que el dato transmitido ha de ser releído en cada acontecimiento para, a través de este, transformar al mundo, muy construccionistamente hablando, no hay construcción de conocimiento -ciencia- si no hay un antecedente cognitivo. 


\section{Definición de "Pedagogía"}

En tanto, la pedagogía, como se ha dicho, proviene del griego: paidos que significa niño y agein que significa guiar o conducir, educación de niños específicamente.

Ha de saberse que el pedagogo, en la Antigua Grecia, era aquel esclavo a quien se le encargaba acompañar a los niños a todos los lugares con el deber de enseñarles las"buenas costumbres de un ciudadano", una buena educación, esta era su labor. Sobresale decir que los acompañaba a la escuela y tenía potestadde corregirles mediante castigos corporales, inclusive.

La pedagogía, como enseñar y educar, tiene su fin último encorregir e instruir a través de la «buena educación», mediante la interiorización de valores como el respeto, amor, sinceridad, honestidad y todos aquellos que dignifiquen a la sociedad humana. La pedagogía como la filosofía pretenden transformar al mundo, liberarlo de alienaciones, encumbrarlo hacia latitudes y altitudes de seres humanos más virtuosos.

Paulo Freire (2010) brinda su definición de pedagogía, a saber:

Enseñar es posibilitar que los alumnos, al promover su curiosidad y volverla cada vez más crítica, produzcan el conocimiento en colaboración con los profesores. El docente no tiene que dedicarse a transmitir el conocimiento, solo debe proponer al alumno elaborar los medios necesarios para construir su propia comprensión del proceso de conocer y del objeto estudiado. (El grito manso, p. 54)

La pedagogía es un proceso de enseñanza-aprendizaje, un acto recíproco en donde los actores educativos, fundamentalmente: docente y discente, se encuentran en tanto posibilitación de aprehensión de contenidos significativos, epistemológicamente hablando.

\section{Definición de "Didáctica"}

El concepto didáctica, en su sentido latino, puede decirse que proviene de los conceptosdocere: enseñar y discere: aprender.

Katya Calderón Herrera (2007) explica que la didáctica es “(...) la teoría general de la docencia. Investiga una disciplina particular de la 
pedagogía, las leyes del proceso unitario de la instrucción y la educación en la clase. Además, debe resolver muchos problemas teóricos" (p. 75).

Puede entenderseque la didáctica está relacionada con la pedagogía; que ambas parten de la siguiente realidad: el ser humano es educable y educa. Así es que el ser humano gestiona teorías para lograr una "instrucción" y las implementa en el proceso educativo: ese conjunto de teorías para dicho fin se le llama Teoría de la Educación.

Calderón Herrera (2007), citando a Santomauro, considera algunas generalidades que explican el sentido práctico de la didáctica:

- Como primer punto determina los fines y los objetivos de la enseñanza.

- $\quad$ Segundo, debe describir el proceso de enseñanza en su forma general y descubrir las leyes de este proceso.

- $\quad$ Tercero, debe derivar principios básicos del aprendizaje.

- Cuarto, debe fijar el contenido de la clase que los niños puede asimilar dado su derecho y las diversas actividades prácticas.

- Quinto, debe formular los principios fundamentales de la organización de clase.

- Sexto, debe informar a los maestros sobre los métodos que ha de utilizar en la enseñanza de los alumnos.

- $\quad$ Séptimo, debe informar acerca de los materiales que el maestro debe utilizar en la clase para ampliar las metas asignadas. (p. 75)

Por su parte Antonio Medina Rivilla y Francisco Salvador Mata (2009), definen didáctica como: "la disciplina o tratado riguroso de estudio y fundamentación de la actividad de enseñanza en cuanto propicia el aprendizaje formativo de los estudiantes en los más diversos contextos" (p. 7). Pues, la pedagogía como acción para guiar y dirigir conciencias, no es lo mismo que la didáctica, la que resulta ser más "lucernario teórico-práctico" para aplicar esas acciones pedagógicas conforme la realidad específica y sus posibles interpretaciones.

\section{Definición de "Andragogía”}

La palabra andragogía se compone de dos palabras de raíces griegas: -andro, hombre, y -ágo, guiar, conducir, es decir: «aquel que guía al hombre». El concepto andragogía, en el campo 
educativo, es pertinente a los ambientes de adultos, o sea, la andragogía es educación de adultos. Este concepto es muy reciente en el léxico educativo y fue acuñado y promulgado por el alemán Alexander Kapp (1876-1941), y posicionado teóricamente, por el estadounidense Malcolm Knowles (1913-1997), con la intención de diferenciar andragogía de pedagogía.

Elbia Vásquez (1985) distingue algunas definiciones de la "educación de adultos", una de ellas es la que remite la UNESCO, a continuación:

(...) designa la totalidad de los procesos organizados de educación, sea cual sea el contenido, el nivel o el método, sean formales o no formales, ya sea que prolonguen o reemplacen la educación inicial dispensada en escuelas y universidades, y en forma de aprendizaje profesional, gracias a las cuales las personas consideradas como adultos por la sociedad a que pertenecen, desarrollan sus aptitudes, enriquecen sus conocimientos, mejoran sus competencias teóricas o profesionales o les dan una nueva orientación, y hacen evolucionar sus actitudes o su comportamiento en la doble perspectiva de un enriquecimiento integral del hombre y una participación en un desarrollo socioeconómico y cultural equilibrado e independiente. (p. 34)

Como modo conclusivo, del retraer estas definiciones de conceptos, se determina que la Teoría de la Educación es un evento cognitivo sumamente complejo, de reflexión de las realidades, conceptos como ciencia, filosofía, pedagogía, andragogía, didáctica, y sus definiciones abren ahora el espacio para ir concluyendo este ensayo, y con ello continuar delimitando la tesis del mismo.

\section{¿Qué es la Teoría de la Educación? ¿Cuál es su relación con la Filo- sofía de la Educación?}

La educación es el medio natural e institucional por el cual el ser humano se compenetra en el conocimiento de las herencias cognitivas de cada generación,convertidas en aprendizajes para la consolidación del ser humano.La educación es socialización de los conocimientos entre las personas, reconociendo, además, que el ser humano es un ser social y por ello la educación se «aprende» entre pares. 
La Teoría de la Educación, en sí misma, se ocupade responder a estas preguntas: ¿porqué enseñar?, ¿cómo enseñar?, ¿qué enseñar? y ¿para qué enseñar?

No obstante, es bueno determinar que lo conveniente es hablar de "teorías de la educación" como un conjunto de ideas que buscan explicar o entender un fenómeno: el educativo y solucionar sus avatares. Estas teorías educativas dependen de un contexto histórico y geográfico. Cada historia, y el devenir educativo, por ende, proveen a la Teoría de la Educación de nuevas y diversas nuevas teorías, las que siempre han pretendido mejorar al sistema y proceso educativo.

La Teoría de la Educación guarda un interés evidentemente racional por clarificar las mejores técnicas y estrategias para educar, pues el acto humano científico es por esencia producto del acto de la razón, acá la educación toma un "tinte científico y filosófico", pues la teoría educativa es un hecho de eventos racionales, es decir, de reflexiones que parten del estudio de la realidad epistemológica.

Encontramos, así, una relación entre la Teoría de la Educación con la filosofía, por lo que nace laFilosofía de la Educación, pues, es que, la filosofía reflexiona sobre el proceso educativo.

La Filosofía de la Educación se dedica a las interpretaciones del proceso educativo, desde sus reflexiones puede emitir teoríaspara entender mejor el proceso educativo de la época y proponer, a la Teoría de la Educación, los mejores "caminos" para educar significativamente.

No es posible una teoría educativa sin una reflexión filosófica del proceso educativo, pues la segunda le brinda "insumos ideales" a la primera para concretizar sus prácticas pedagógicas y didácticas.

\section{Las Teorías educativas que nacen del filosofar}

Eugenia Brenes y Marta Porras (2012) conciben los siguientes tipos de teorías educativas: las empíricas, las axiológicas, las filosóficas, las parciales y generales:

\section{a. Teorías empíricas}

Según Brenes y Porras (2012), estas teorías son aquellas que se apoyan en la psicología, por lo tanto, tienen carácter científico al validar la experimentación. Afirman que: «la práctica había de estar avalada 
por una teoría, que era replanteada según fuesen los resultados de aquella» (p. 8).Es decir, estas teorías, convalidan el carácter científico de la educación al existir la verificabilidad de los acontecimientos por medio de las comprobaciones. De hecho, esto es lo que valida a las teorías en su certeza epistemológica.Como ejemplo de este tipo de teorías, se identifica a las que se incluyen en la escuelapositivista, con representantes como Augusto Comte (1798-1857) y Herbert Spencer (1820-1903), quienes fundamentaban su teoría en la aplicación del método científico como medio de verificabilidad de los fenómenos.

\section{b. Teorías axiológicas}

Son teoríasdecarácter antropológico y moral que proponen normas de conducta que, a su vez, definirán conceptos debien y de mal. Estas teorías incluyen perspectivas de tipo cultural, contextual y circunstancial, pues cada código ético depende de estas realidades sociales, en las que el individuo se desarrolla.

Entendemos que el ser humano es un ser moral, capacidad que parte de su inteligencia que le permite generar juicios de valor.

Un ejemplo de este tipo de teoría se encuentra en la propuesta pedagógica y filosófica de María Montessori (1870-1952), quien propone una educación moral y religiosa, como lo reseñan Soto y Bernardini(2009): "Para M. Montessori, la verdadera educación del sentido moral es educación al amor" (p. 193). (...) la educación religiosa de los niños no es algo añadido, un complemento respetuoso de las tradiciones, sino que es "casi el fin último de gran parte de la educación que el método se propone", además de una "rica fuente de alegría y de grandeza" (p. 194).

\section{c. Teorías filosóficas}

Brenes y Porras (2012) categorizan lo que deciden llamar "teorías filosóficas", pues consideran son las más concordantes con la Teoría de la Educación, debido a que la teoría educativa es más de tintes filosóficos (p. 9).

La teoría filosófica es, como se ha dicho, una comprensión e interpretación del mundo, desde la particularidad del filósofo, pero también desde las escuelas filosóficas (existencialista, racionalista, personalista, 
etcétera) a las que tiende a dirigirse, o apreciar; ello hace del filósofo un teórico que desde un punto de vista específico emite su discurso.

Una teoría filosófica puede producir teorías educativas, por ejemplo,el filósofo suizo Jean Jacques Rousseau (1712-1778)ideó una teoría educativa que considera que el ser humano es bueno por naturaleza pero que la sociedad le corrompe, pero una "correcta"educación (la que produce a un ser humano virtuoso) puede mejorar a la sociedad y al individuo.

Otro ejemplo, lo encontramos en el pensamiento de Jacques Maritain (1882-1973), quien consideró que "el fin principal de la educación, en un sentido muy amplio, consiste en ayudar al pequeño hombre a alcanzar su plena formación humana" (Soto y Bernardini, p. 257). Así se desarrolló la teoría educativa denominada: humanismo integral católico.

\section{d. Teorías parciales y generales}

Según Brenes y Porras (2012),las parcialesversan acerca de un tema concreto en la pedagogía (fenómenos específicos, casos particulares),su número es indefinido,por lo tanto;y las segundas, las generales, tratan sobre varios temas o dimensiones de la pedagogía, todas aquellas teorías educativas sistemáticamente definidas (La teoría de John Dewey, la de Iván Illich, la de Karl Marx, la de Antonio Gramsci, etcétera).

\section{Algunos Modelos Pedagógicos que nacen de esas teorías educativas}

Flórez Ochoa (2005) da su definición de modelo pedagógico, a saber:

(...) la representación del conjunto de relaciones que describen un fenómeno o una terapia. Un modelo pedagógico es la representación de las relaciones que predominan en una teoría pedagógica, es también un paradigma que puede coexistir con otros y que sirve para organizar la búsqueda de nuevos conocimientos en el campo de la pedagogía (p. 175).

A su vez, Flórez Ochoa, identifica cinco modelos pedagógicos: el tradicional, el romántico, el conductista, el cognitivo o constructivista y el social. A continuación, se explican sus características: 


\begin{tabular}{|l|l|}
\hline \multicolumn{1}{|c|}{ Modelo pedagógico } & \multicolumn{1}{|c|}{ Sus características } \\
\hline Modelo pedagógico tradicional & $\begin{array}{l}\text { Centrado en la recepción de contenidos; su meta } \\
\text { es formar carácter; la relación maestro-alumno } \\
\text { es vertical; y su método es transmisionista e } \\
\text { imitativo, así como repetitivo. }\end{array}$ \\
\hline Modelo pedagógico romántico & $\begin{array}{l}\text { Centrado en la naturaleza del niño; su meta es } \\
\text { formar libertad individual o espontaneidad; la } \\
\text { relación maestro-alumno es vertical, en don- } \\
\text { de el maestro es considerado un auxiliar del } \\
\text { aprendizaje; y su método está fundamentado } \\
\text { en la búsqueda de ambientes que permitan la } \\
\text { libertad de expresión. }\end{array}$ \\
\hline Modelo pedagógico conductista & $\begin{array}{l}\text { Centrado en la transmisión de la información } \\
\text { dispuesta para ello; su meta es el moldeamiento } \\
\text { de una conducta; la relación maestro-alumno es } \\
\text { vertical, en donde el maestro es un intermedia- } \\
\text { rio que ejecuta; ysu método está fundamentado } \\
\text { en la fijación de los contenidos por aprender, } \\
\text { su refuerzo sistemático y el control constante. }\end{array}$ \\
\hline $\begin{array}{l}\text { Modelo pedagógico cognitivo o } \\
\text { constructivista }\end{array}$ & $\begin{array}{l}\text { cimiento; su meta es el desarrollo intelectual } \\
\text { respetando la individualidad de los actores en el } \\
\text { sistema pedagógico; la relación maestro-alumno } \\
\text { es vertical en donde el maestro es facilitador y es- } \\
\text { timulador de experiencias; y su método consiste } \\
\text { en la «creación» de experiencias y ambientes que } \\
\text { hagan del alumno un investigador e indagador. }\end{array}$ \\
\hline $\begin{array}{l}\text { Se centra en la socialización del conocimiento; } \\
\text { su meta es la producción social, el trabajo coo- } \\
\text { perativo para solucionar problemas; la relación } \\
\text { maestro-alumno es recíproca inmediata; y su } \\
\text { método consiste en el trabajo productivo, me- } \\
\text { diante la discusión y la crítica }\end{array}$ \\
\hline pedagógico social
\end{tabular}

Fuente: Flórez, R. (2005). Pedagogía del conocimiento, p. 176-198.

La Teoría de la Educación es, en sí misma, una manera de formular teorías educativas, percibiendo los diferentes modos (modelos) de implementar la educación; es decir, de llevar a la práctica lo reflexionado por el pedagogo que investiga, a través de estrategias o modelos pedagógicos. El actuar filosóficamente es pertinente en el buen docente, al interpretar las realidades, "hacer epistemología".

Comprendiendo que la Filosofia de la Educación es un ingrediente más en la Teoría de la Educación, una“colaboradora" en la formulación de 
teorías educativas aplicadas a una situación, visualizamos que la Filosofía de la Educación le da insumos cognitivos a la Teoría de la Educación mediante sus reflexiones y estimaciones a las preguntas educativas.

Pero esto ha de hacerse integralmente desde y siempre en la preparación de todo docente para que estime, desde su personalidad e introspección del proceso educativo, los modelos y teorías educativas que mejor le resulten en su práctica y en beneficio propio y de sus alumnos. Por ejemplo, existen alumnos, por diversas razones, que requieren de un modelo pedagógico conductista, en cambio, otros de un modelo constructivista.

\section{Las Filosofías de la Educación, aportes a las teorías educativas}

Existen«filosofías de la educación» identificadas por «escuelas», algunas se pueden identificar con el siguiente cuadro:

\begin{tabular}{|l|l|}
\hline \multicolumn{1}{|c|}{ Escuela filosófica } & \multicolumn{1}{c|}{ Sus características } \\
\hline Escuela idealista & $\begin{array}{l}\text { Esta escuela fundamenta su interés pedagógico en la com- } \\
\text { prensión de la espiritualidad de la persona; por lo tanto, en } \\
\text { su característica de ser "con libre albedrío". No busca iden- } \\
\text { tificar a la persona como un objeto, el maestro idealista, y } \\
\text { el sistema educativo idealista, buscan que el estudiante ex- } \\
\text { terne sus ideas, que se realice como persona única e irrepe- } \\
\text { tible. El maestro es un motivo por emular, un modelo. Re- } \\
\text { presentantes son: Platón, George Hegel y Emmanuel Kant. }\end{array}$ \\
\hline Escuela realista & $\begin{array}{l}\text { Su interés pedagógico radica en el principio de comprender } \\
\text { que "yo soy distinto del mundo", y el mundo no soy yo, } \\
\text { sino que yo habito en este. El maestro debe llevar la inicia- } \\
\text { tiva pedagógica, implementar el "espíritu científico" en los } \\
\text { estudiantes. Se citan a Aristóteles, Santo Tomás de Aquino, } \\
\text { Francis Bacon o John Locke. }\end{array}$ \\
\hline Escuela pragmatista & $\begin{array}{l}\text { Esta escuela mantiene la postura de los realistas, pero a ello } \\
\text { suman el énfasis de que el mundo es cambiante y, en este, el } \\
\text { ser humano es responsable por sus acciones, pues lo altera- } \\
\text { mos con ellas. La mayoría de los pragmatistas niegan la fa- } \\
\text { ceta espiritual del ser humano propuesta por los idealistas. } \\
\text { El maestro proveerá de discusiones que considerará como } \\
\text { importantes. Los exponentes son Charles Sanders Peirce, } \\
\text { William James o John Dewey. }\end{array}$ \\
\hline
\end{tabular}




\begin{tabular}{|l|l|}
\hline \multicolumn{1}{|c|}{ Escuela filosófica } & \multicolumn{1}{c|}{ Sus características } \\
\hline Escuela existencialista & $\begin{array}{l}\text { Fundamenta su propuesta en el discurso acerca de la liber- } \\
\text { tad humana y la individualidad de la persona: su autentici- } \\
\text { dad. Le da mayor iniciativa al docente y a los contenidos. } \\
\text { En la sociedad "tendemos a dejar de ser auténticos", por } \\
\text { eso es fundamental motivar la personalidad única de cada } \\
\text { estudiante: su creatividad. El maestro ha de colaborar con } \\
\text { cada estudiante para que se realice como persona desde su } \\
\text { libertad e identidad. Sobresalen: Sören Kierkegaard, Jean } \\
\text { Paul Sartre, Albert Camus, Simone de Beauvoir, Karl Jas- } \\
\text { pers, Martin Heidegger, entre otros. }\end{array}$ \\
\hline Escuela progresista & $\begin{array}{l}\text { Esta escuela considera fundamental velar por los intereses } \\
\text { del estudiante, a quien se le inculca la posibilidad de solu- } \\
\text { cionar problemas; no simplemente de recibir la información } \\
\text { programada por una institución, o sistema, sino además de } \\
\text { enseñar a hacer con el conocimiento dado. El estudiante se } \\
\text { realiza, o se siente satisfecho, en la elaboración de crítica a } \\
\text { los hechos, acontecimientos y situaciones. Representantes } \\
\text { son John Dewey y Kilpatrick. }\end{array}$ \\
\hline Escuela marxista & $\begin{array}{l}\text { Esta escuela guardamostrar al trabajo como evento humano } \\
\text { que le dignifica y, por lo tanto le humaniza. El sistema edu- } \\
\text { cativo marxista se define en un enfrentamiento a lo que el } \\
\text { mismo Karl Marx (1818-1883) llamó enajenación humana, } \\
\text { identificando con ello a las alienaciones religiosas, filosófi- } \\
\text { cas, políticas e incluso sociales que impiden la autonomía } \\
\text { personal: pensar desde sí mismo. Todo adoctrinamiento con } \\
\text { tintes capitalistas debería ser erradicado del sistema social. } \\
\text { El trabajo es el discurso individual y social, el cual permi- } \\
\text { te que la persona progrese al expresar la solidaridad como } \\
\text { objetivo axiológico primordial. Sobresalen como en esta } \\
\text { escuela Karl Marx, Anton Makarenko y Antonio Gramsci. }\end{array}$ \\
\hline $\begin{array}{l}\text { El personalismo encuentra en la persona su centro de inte- } \\
\text { rés. Esta escuela aboga por enseñar a vivir sin estar bajo los } \\
\text { intereses de los gobiernos, que políticamente imprimen sus } \\
\text { intereses en las directrices educativas. Emmanuel Mounier } \\
\text { es su gran representante. }\end{array}$ \\
\hline
\end{tabular}

\section{Síntesis de teorías educativas influyentes en la educación actual desde los filósofos}

Respecto de teorías educativas implícitas e influyentes en la educación actual, se determinan algunas de estas teorías identificándolas y definiéndolas, al lector le proveo de este cuadro para ello: 


\begin{tabular}{|c|c|}
\hline Teoría educativa & Sus características \\
\hline Teoría rousseauniana & $\begin{array}{l}\text { Jean Jacques Rousseau (1712-1778) determina, epistemológicamente, } \\
\text { que el ser humano es bueno, pero en el contacto con la sociedad se } \\
\text { corrompe. El ideal del maestro es el amigo educativo, el maestro que } \\
\text { acompaña y corrige a partir de la buena fe. Lo anterior conlleva a un } \\
\text { nuevo tipo de persona educada por un maestro, el mejor, el virtuoso y } \\
\text { el justo, para que se instruya en la naturaleza, alejado de la civilización } \\
\text { - que en realidad es alienación humana-, y así descubra lo que real- } \\
\text { mente es bueno o malo. La "buena educación" consiste en lograr un } \\
\text { hombre racional. Por eso, siempre, el ser humano necesita de un guía } \\
\text { o maestro. El papel de autoridad del maestro queda enfático en lograr } \\
\text { al estudiante virtuoso. }\end{array}$ \\
\hline Teoría de Pestalozzi & $\begin{array}{l}\text { Johann Pestalozzi (1746-1827) define su teoría pedagógica relacionán- } \\
\text { dola con la creencia de que la naturaleza humana en sí misma es buena } \\
\text { aunque corrompida, sea por incidentes externos o internos a la persona } \\
\text { humana. Y que por lo tanto la educación "natural" es la correcta, es } \\
\text { decir, bajo el contacto mismo con la naturaleza. Pestalozzi buscaba re- } \\
\text { ferenciar la necesidad del alumno por su perfeccionamiento, a partir de } \\
\text { su intelecto aplicado con el favorecimiento del proceso educativo en la } \\
\text { sociedad y desde los sentimientos: el amor, la confianza, la gratitud, la } \\
\text { obediencia, la conciencia del deber y del derecho. }\end{array}$ \\
\hline Teoría marxista & $\begin{array}{l}\text { En la educación marxista se pretende eliminar el adiestramiento pro- } \\
\text { piciado por la educación ideológica y manipulada por los poderosos, } \\
\text { que hace de los seres humanos simples máquinas. La vida colectiva/ } \\
\text { comunista es el fundamento esencial de su concepción didáctica (edu- } \\
\text { cación de la colectividad). De este modo se justifican los medios de } \\
\text { organización y la disciplina. Se le da sumo valor al trabajo en la pro- } \\
\text { puesta pedagógica, así como gran valor a la adquisición del conoci- } \\
\text { miento y a la investigación. Las bibliotecas y los laboratorios ocupan } \\
\text { una relevancia evidente }\end{array}$ \\
\hline Teoría de Montessori & $\begin{array}{l}\text { María Montessori (1870-1952)entiende que la personalidad del niño } \\
\text { está demarcada por incidentes internos, intrínsecos, por lo que, el pa- } \\
\text { pel del docente no será de instruirle o adiestrarle, sino de guiarle, de } \\
\text { la mejor manera: motivándole. Al niño se le debe permitir expresarse } \\
\text { en libertad, no "atarle" a conocimientos o acciones ya predispuestas } \\
\text { por un sistema o una persona que se encarga de ello. La conformación } \\
\text { del ambiente educativo apropiado es fundamental para propiciar tal } \\
\text { libertad (libertad pedagógica) y tal posibilidad de expresividad, o sea, } \\
\text { de educación. El aspecto moral y religioso son relevantes en el modelo } \\
\text { montessoriano, así como la socialización. }\end{array}$ \\
\hline $\begin{array}{l}\text { Teoría de Lev S. } \\
\text { Vygotsky }\end{array}$ & $\begin{array}{l}\text { En Vygotsky (1896-1934) la educación se da en un contexto tal, y } \\
\text { ese contexto le influye y determina, le transforma constantemente. Él } \\
\text { concluyó que la transmisión del pensamiento se da en relación con la } \\
\text { experiencia (sistema mediatizador) al lenguaje humano, el cual es un } \\
\text { evento que ha aparecido por una cuestión de necesidad, la de comu- } \\
\text { nicarse entre los individuos. El poder de la palabra se encuentra en } \\
\text { el contexto de lo intelectual, que define el desarrollo de la persona } \\
\text { en cuánto expresividad del pensamiento y desarrollo de la conciencia. }\end{array}$ \\
\hline
\end{tabular}




\begin{tabular}{|c|c|}
\hline Teoría educativa & Sus características \\
\hline Teoría de Dewey & $\begin{array}{l}\text { John Dewey (1859-1952) considera que solo es proceso educativo el } \\
\text { que está contextuado en la institución denominada como escuela (o } \\
\text { bien las instituciones educativas en general). La educación tiene, como } \\
\text { principio esencial de acción, la socialización; es decir, llevar a la per- } \\
\text { sona a involucrarse en la comunidad y en sus influencias, y viceversa; } \\
\text { la educación debe ser democratizada y preparada para una sociedad } \\
\text { de la democracia. }\end{array}$ \\
\hline Teoría de Maritain & $\begin{array}{l}\text { Jacques Maritain (1882-1973) dio sumo valor al aporte histórico de } \\
\text { la filosofía a la pedagogía y a la educación en general. Para él, los } \\
\text { fines de la educación no solamente han de ser claros, sino, además, } \\
\text { evidentemente provechosos para el bienestar de todo actor del pro- } \\
\text { ceso educativo, es decir, la persona misma y la institución, pero esto } \\
\text { debe verse como parte de un proceso, pues la educación es inacabable. } \\
\text { Para la educación no solo es importante el bienestar personal y social, } \\
\text { sino que se suman el interés educativo científico y filosófico por la } \\
\text { búsqueda de la verdad, como el máximo bien. En su propuesta edu- } \\
\text { cativa sedemarca, profundamente, un interés por la doctrina cristiana, } \\
\text { una teoría educativa en la que se defiende el encuentro con Dios en el } \\
\text { mismo sistema y proceso educativo, como una relación que lleva a la } \\
\text { perfección humana por el amor. }\end{array}$ \\
\hline Teoría de Freire & $\begin{array}{l}\text { Paulo Freire (1921-1997) realiza un estudio crítico que genera una } \\
\text { perspectiva educativa fundada en el análisis de la educación desde la } \\
\text { incidencia de la política en ella, y como la política determina los cami- } \\
\text { nos educativos al implantar planes de estudio y demás a las personas } \\
\text { que se educan y educa: les oprimen.El interés pedagógico de Freire es } \\
\text { concientizar esa injerencia de los sistemas políticos neoliberales en la } \\
\text { educación, convirtiéndola en sistemas educativos alienantes, por eso } \\
\text { su opción es la de velar y dirigir una revolución pedagógica por la } \\
\text { justicia social. Entiéndase una propuesta educativa que permita pensar } \\
\text { críticamente para elaborar soluciones, que liberen a los individuos de } \\
\text { las injusticias sociales. } \\
\text { En cuanto a la tarea y personalidad del educador, Freire expone entre } \\
\text { sus ideas un tipo de educador humanista, en cuanto busca dignificar } \\
\text { el proceso educativo dignificando a sus actores, al discente, y a sí mis- } \\
\text { mo, esa dignificación se dará mediante un acto educativo basado en el } \\
\text { diálogo, en la democratización del acto, posibilitando el pensamiento } \\
\text { crítico recíproco. } \\
\text { La utopía educativa de Freire encuentra un punto focal esencial: edu- } \\
\text { cadores y educandos críticos, reflexivos y de la praxis, aun en contra } \\
\text { de los sistemas enajenantes de gobernantes, o políticos, neoliberales. } \\
\text { Homólogo al pensamiento de Freire, y que sirva esto para complemen- } \\
\text { tar lo expresado en este subtítulo, Enrique Dussell (1996), y la filosofía } \\
\text { de la liberación, funda su teoría en la consideración de una filosofía de } \\
\text { la periferia, es decir, desde los oprimidos. Pretende lo que él llama una } \\
\text { proximidad, que bien podría ser interpretado como una identificación } \\
\text { pedagógica con el espíritu de fraternidad y solidaridad: } \\
\text { La pedagogía de la liberación latinoamericana, radicalmente, dedica } \\
\text { su discurso en favor de la justicia social, y este discurso ha de ser } \\
\text { llevado a las instituciones educativas y sus aulas. }\end{array}$ \\
\hline
\end{tabular}




\begin{tabular}{|l|l|}
\hline \multicolumn{1}{|c|}{ Teoría educativa } & \multicolumn{1}{c|}{ Sus características } \\
\hline Teoría de Illich & $\begin{array}{l}\text { Iván Illich (1926-2002) define su tesis como la teoría de la desescola- } \\
\text { rización, pues considera que la escuela, o sistema educativo formal, se } \\
\text { halla en crisis; "la escuela" ha perdido credibilidad como institución } \\
\text { educativa en sus fines y principios, en mucho por su politización pau- } \\
\text { latina pero con fuerza. Para Illich las burocracias han causado graves } \\
\text { crisis sobre la educación al apropiarse de la "imaginación social", que } \\
\text { han fijado reglas que indican lo que es válido. En concordancia con } \\
\text { las ideas de Paulo Freire, Illich asume la necesidad de abandonar una } \\
\text { escuela que aliena, por ello "la desescolarización", que equivaldría a } \\
\text { una desinstitucionalización necesaria porque no ejecuta una real auto- } \\
\text { nomía responsable en los estudiantes. }\end{array}$ \\
\hline
\end{tabular}

\section{La epistemología filosófica y la teoría educativa}

¿Qué se sabe?, ¿qué se aprende?, ¿por qué se aprende?, ¿cómo se aprende?, ¿para qué se aprende?, son las "preguntas epistemológicas educativas", por ende, filosóficas.

La epistemología, o estudio sobre el conocimiento (cómo conocemos, qué conocemos, porqué conocemos, para qué conocemos), se halla enmarcada por diversos aspectos: la ciencia, las teorías, las pedagogías, la inteligencia, el entorno cultural, el entorno físico, la historia, la herencia genética, la política educativa, las interacciones sociales, la tecnología, entre otros. Pero esta también les influye a estos aspectos.

Somos "seres epistemológicos", que de igual manera que si no se practica el acto memorístico, este se atrofia, de igual manera el acto epistemológico acontecerá así.

Johan Hessen (2007) manifiesta que el conocimiento se manifiesta en la relación entre el sujeto y un objeto, así que el "verdadero problema epistemológicose sitúa en esa relación. (p. 71)En los campos educativos "ese problema" epistemológico se da con el encuentro entre el docente y el discente debido a sus individualidades cognitivas, existenciales e irracionales, porque pueden discurrir en lo que consideran, cada uno de ellos, como la verdad, surgiendo de esta manera un desacuerdo de inteligencias y opiniones. Sin embargo, el desacuerdo también puede generar conocimiento nuevo.

El dilema epistemológico más se inclina hacia el concepto de verdad y su posibilidad mediante el acuerdo dialéctico, pues, filosófico.Carlos Rojas Osorio (2006) se refiere al "consenso racional" de este modo: “(...) la verdad no existe en un empíreo, sino que son seres 
humanos quienes se ocupan del saber, quienes determinan la verdad o falsedad de las teorías" (p. 152).

La inteligencia racional es una facultad a la que todos los seres humanos tienen acceso porque les es natural; todo ser humano es inteligente, aunque, y por estimaciones psicológicas o intuitivas, unos individuos son más inteligentes que otros. La inteligencia también es desarrollada en tiempo y espacio; depende esta no solo de situaciones biológicas o genéticas que la definan, sino de entornos y contextos educativos, así como de la calidad de vida en general, así como de relaciones interpersonales que influyen y determinan la personalidad y capacidad cognitiva de la persona.

La inteligencia humana ha desarrollado el lenguaje como su medio de comunicación, el lenguaje se vale de signos y sonidos: el lenguaje posibilita la educación.

En tanto la educación es aprehensión de conocimientos comunicados, posibilitado, ello, por el lenguaje, es que el proceso educativo debe conllevar un eficiente plan de comunicación de los aprendizajes, acá no solamente los aspectos burocráticos-tecnocráticos son relevantes para llegar a la eficiencia educativa, sino que, especialmente, el acto comunicativo del saber en el aula, en la relación docente-discente constituyen especialmente la optimización epistemológica del proceso de enseñanza- aprendizaje.

Al respecto Rolando Pinto Contreras (2012) anota que "el docente de aula tiene la responsabilidad de organizar los componentes del proceso formativo para lograr aprendizajes significativos y encantar al educando con la educación. Se comienza a hablar de un docente líder innovador de la práctica educativa" (p. 126). La educación, como proceso, encuentra en la relación cordial entre educando y educador su momento más oportuno para gestar ciencia.

En este apartado, y finalizando la exposición del asunto en el ensayo, se puede determinar que la epistemología como filosofía cala en la teoría educativa como conducente de la educación sistemática que posibilita no solo el análisis de la realidad y el deseo por conseguir un ser humano más humanizado, más virtuoso, más solidario, más pleno. Además, posibilita una relación intelectual entre discente y docente.

Pero en el caso específico de la tesis sostenida para este ensayo, la relevancia se muestra a partir de propiciar a un docente universitario, desde la universidad, más ecuánime con el tema racional 
y reflexivo, por ende, la educación epistemológica le proporciona al docente, y futuro docente, de un bagaje de conocimientos e ideas que le facilitan interpretar y leer los acontecimientos, le agilizan en las capacidades de evitar dogmatismos cognitivos y le abren a nuevas y creativas formas de educar.

Lo anterior porque la epistemología le brinda a la Teoría de la Educación conceptos y argumentos filosóficos que le facilitan adaptar los intereses más beatos de la educación y el educador a las realidades. Una teoría educativa sin "la participación" de la filosofía, se insiste,no deja de ser un discurso, o tiende a ello, desubicado, descontextualizado.

Y ¿por qué, la tan teórica epistemología, facilita la práctica educativa desde la teoría educativa?, pues porque la epistemología es lectura misma de lo que sucede.

Ahora bien, la epistemología filosófica le hereda a la teoría educativa todo su bagaje de aportes a la práctica pedagógica mediante la Filosofía de la Educación, que no deja de ser epistemología.

\section{Conclusiones}

La Teoría de la Educación es un evento complejo en el evolucionar de la educación como proceso y sistema, en tanto, es intento humano por comprender, desde la reflexión, el actuar educativo: cómo enseñar, cómo educar, qué es educar, para qué educar, etcétera, por eso no puede desvincularse la Teoría de la Educación de la Filosofía, especialmente ésta en cuanto Epistemología, más aún, con la Filosofía de la Educación, pretende hallar, desde el análisis de la realidad, lo que sucede en el devenir educativo para que con sus interpretaciones, desde las ideas, proponerle a la Teoría de la Educación nuevas ideas para formular nuevos modelos pedagógicos, acordes a las distintas realidades (contextos).

El docente o el estudiante de docencia no pueden ser exceptuados, por el sistema educativo superior, de la concepción de la Filosofía de la Educación ni de la Epistemología, si ello llegase a suceder la Teoría de la Educación "flaquea" en sus buenas intenciones, y así, entonces, surge un sesgo cognitivo considerable en la persona que educa o se prepara para educar.

Tanto la Teoría de la Educación como la Filosofía de la Educación (Epistemología Educativa) fundamentan en el (futuro) docente, 
una gama de concepciones y reflexiones acerca de lo educativo, que le permitirán mayor creatividad y comprensión del proceso educativo en bienestar de los educandos y de su misma y propia metodología y estrategias para educar.

Es consecuente y necesario con el modelo educativo liberador, el que evita alienaciones o enajenaciones, provee al (futuro) docentede estudios epistemológicos filosóficos. En el devenir de nuestros actuales modelos, currículos y propuestas educativas universitarias, el campo de lo reflexivo, o sea, lo filosófico, se ha devenido en ocultar y pormenorizar el papel de la filosofía, todo esto causado por un interés neoliberal evidente, una inclinación por generar "mercaderes".

La universidad puede envolverse fácilmente en esa ostentación por "producir sujetos neoliberales", sin concepto, por lo tanto, de individuos/personas solidarias y reflexivas. La epistemología toma así un papel fundamental en brindar "una espiritualidad pedagógica", específicamente, hablando en los campos de la Educación.

Si bien es preocupante que en casi todos los ambientes universitarios el campo de lo filosófico se ha desvanecido, o bien, desmeritado, es mucho más preocupante que ello pueda suceder en las escuelas o facultades de la Educación propiamente. El papel formador humanizante del maestro, del profesor, del docente es el más relevante en la sociedad, pero si este carece de "espiritualidad pedagógica" su discurso es meramente un discurso vacío de sentido humanístico y repleto de vocablos de mercado.

Es urgente que la epistemología sea un acicate en toda propuesta educativa superior, pero especialmente en la preparación de los docentes, de todo tipo y toda área, con ello, y consecuentemente con la implementación de la reflexión en cada uno tendremos una sociedad realmente abierta al discurso de la racionalidad, de la colectividad y de la defensa de la justicia social.

Saber ¿qué se sabe?, ¿qué se aprende?, ¿por qué se aprende?, ¿cómo se aprende?, ¿para qué se aprende?, le da sentido a la educación y a la vida, y esto no surge sino desde las preguntas epistemológicas por antonomasia: ¿cómo conocemos, qué conocemos, porqué conocemos, para qué conocemos? Educación desligada de epistemología es educación sin sentido, Teoría de la Educación sin Filosofía de la Educación, es por ende, educación sin epistemología. 


\section{Referencias bibliográficas}

Brenes, E. y M. Porras. (2012). Teoría de la educación. San José, Costa Rica: EUNED.

Bunge, M. (1998). La ciencia: su método y su filosofía. Buenos Aires, Argentina: Editorial Sudamericana.

Bunge, M. (1984). Ciencia y desarrollo. Buenos Aires, Argentina: Ediciones Siglo Veinte.

Calderón, K. (2007). La didáctica hoy, concepciones y aplicaciones. San José, Costa Rica: EUNED.

Flórez, R. (2005). Pedagogía del conocimiento. Bogotá, Colombia: McGraw-Hill.

Freire, P. (2010). El GritoManso.México: Siglo XXI.

Hessen, J. (2007). Teoría del conocimiento. México:Editores Mexicanos Unidos S.A.

Medina, A y Salvador, F (2009). DidácticaGeneral.Madrid: Pearson. Recuperado de http:/190.202.118.250/diseno2/cnifpm_web/media/ $\mathrm{k} 2 / \mathrm{attachments/didactica/coleccion-didactica-didactica-general.pdf}$

Michel, J.A. (2006). Sobre el estatuto epistemológico de las ciencias. Revista de Teoría y Didáctica de las Ciencias Sociales, 11, 139-157.

Morales, C., Cordero, G., López, J., Serrano, A. Rojas, C. y Mora, A. (2004). Heredia, Costa Rica: Cuadernos Prometeo N ${ }^{\circ} 32$.

Pinto, R. (2012). Principios filosóficos y epistemológicos del ser docente. San José, Costa Rica: CECC/SICA.

Rojas, C. (2006). La ciencia como lenguaje. Heredia, Costa Rica: Colección Prometeo $\mathrm{N}^{\circ} 35$.

Salazar, M. (2006). Sobre el estatuto epistemológico de las ciencias de la educación. Revista de Teoría y Didáctica de las Ciencias Sociales, 11 (11). Recuperado de http://www2.scielo.org.ve/scielo. php?script=sci_arttext\&pid=S1316-95052006000100007\&ln$\mathrm{g}=\mathrm{es} \& \mathrm{nrm}=$ Iso\&tlng $=\mathrm{es}$

Soto, J. y Bernardini,A.. (2009). La educación actual en sus fuentes filosóficas. San José, Costa Rica: EUNED.

Vásquez, E. (1985). Principios y técnicas de educación de adultos. San José, Costa Rica: EUNED.

Zubiri, X. (2010).Cincolecciones de filosofia. Madrid, España: Alianza Editorial. 